\title{
High preoperative Glasgow prognostic score is a negative prognostic factor for patients with endometrial carcinoma
}

\author{
KOHEI NAKAMURA, KENTARO NAKAYAMA, TOSHIKO MINAMOTO, TOMOKA ISHIBASHI, \\ KAORI SANUKI, HITOMI YAMASHITA, RURIKO ONO, HIROKI SASAMORI, \\ TAKAYOSHI KOMATSU-FUJI, MASAKO ISHIKAWA and SATORU KYO
}

\author{
Department of Obstetrics and Gynecology, Shimane University School of Medicine, Izumo, Shimane 693-8501, Japan
}

Received September 8, 2017; Accepted December 8, 2017

DOI: $10.3892 / \mathrm{mco} .2018 .1551$

\begin{abstract}
The aim of the present study was to determine the prognostic value of the Glasgow prognostic score (GPS) in endometrial carcinoma (EC). Patients with EC who underwent surgery at the Shimane University Hospital between January 1997 and December 2013 were enrolled $(n=118)$. The associations between pretreatment GPS and clinical parameters, including age, histological type, International Federation of Gynecology and Obstetrics stage, tumor grade, carbohydrate antigen 19-9 and carcinoembryonic antigen levels, progression-free survival (PFS), and overall survival (OS), were investigated. Survival analysis was performed with the Kaplan-Meier method, and prognostic factors were evaluated with Cox's proportional hazards regression model. A high pretreatment GPS was associated with advanced clinical stage, histological type and tumor grade $(\mathrm{P}<0.001, \mathrm{P}=0.007$ and $\mathrm{P}=0.006$, respectively). Multivariate analysis identified a high GPS as an independent negative prognostic factor for PFS and OS ( $\mathrm{P}=0.025$ and $\mathrm{P}=0.044$, respectively). Therefore, a high pretreatment GPS has prognostic value and the potential to be a predictive marker for surgical outcome in patients with EC. Evaluation of pretreatment GPS may aid in the identification of high-risk populations, which may improve treatment selection and patient outcomes.
\end{abstract}

\section{Introduction}

The most recently reported estimate of the annual global incidence of endometrial carcinoma (EC) is 320,000 new cases (1), making it the most common gynecological malignancy (2), with an estimated annual global mortality of 76,000 (1). The surgical management and prediction of

Correspondence to: Dr Kentaro Nakayama, Department of Obstetrics and Gynecology, Shimane University School of Medicine, Enyacho 89-1, Izumo, Shimane 693-8501, Japan

E-mail:kn88@med.shimane-u.ac.jp

Key words: endometrial carcinoma, Glasgow prognostic score, overall survival, progression-free survival outcome for patients with EC are guided by the International Federation of Gynecology and Obstetrics (FIGO) staging system (3). However, patients with the same disease stage may experience very different clinical courses $(1,4)$. To elucidate the reasons for these differences, several investigators have evaluated the effect of various tumor attributes on outcomes to delineate prognostic factors, such as histological subtype and FIGO stage (4-6). Unfortunately, preoperative evaluations generally require invasive, costly and time-consuming procedures, such as fractional curettage, transvaginal ultrasonography, magnetic resonance imaging, or hysteroscopic assessment (1,7-9). Early detection and improvements in surgical techniques and chemotherapy have contributed to improvements in prognosis. However, precise predictions of prognosis remain elusive, although they are crucial for optimal treatment decisions.

Previous studies of various cancer types have reported that cancers associated with a systemic inflammatory response are associated with poorer prognosis (10-12). In particular, the Glasgow prognostic score (GPS) is useful for predicting prognosis in a number of cancer types (13-16). The GPS is derived from an inflammation-based prognostic scoring system, including serum C-reactive protein (CRP) and albumin levels. A high pretreatment GPS has been reported to be a poor prognostic factor for patients with cervical and ovarian carcinomas (17-20), but it has not been evaluated thoroughly in EC. Although the prognosis of EC is generally favorable (21), it is poor for a proportion of the patients. Therefore, the aim of the present study was to elucidate the clinical impact of a high pretreatment GPS in patients with EC.

\section{Patients and methods}

Patients. The present study was approved by the Ethics Committee of Shimane Medical University. A total of 118 patients with EC who underwent surgery at the University Hospital of Shimane (Izumo, Japan) between January 1997 and December 2013 were investigated. Patients with insufficient data, non-surgical treatment, secondary malignancies and hematological diseases were excluded.

Diagnosis was based on conventional morphological examinations of hematoxylin and eosin-stained sections, and tumors were classified according to the World Health 
Table I. Clinical characteristics of the patient population $(n=118)$.

\begin{tabular}{lc}
\hline Characteristics & No. of patients $(\%)$ \\
\hline Age at diagnosis, years & \\
$<60$ & $55(47)$ \\
$\geq 60$ & $63(53)$ \\
FIGO stage & \\
I, II & $79(67)$ \\
III, IV & $39(33)$ \\
Histology & \\
Endometrioid & $99(84)$ \\
Other & $19(16)$ \\
Grade & \\
G1 & $53(45)$ \\
G2, G3 & $65(55)$ \\
Pretreatment GPS & \\
0 & $91(77)$ \\
1 & $19(16)$ \\
2 & $8(7)$ \\
CA19-9, U/ml & \\
$<37$ & $93(79)$ \\
$\geq 37$ & $25(21)$ \\
CEA, ng/ml & \\
$<5.0$ & $97(82)$ \\
$\geq 5.0$ & \\
\hline
\end{tabular}

CA19-9, carbohydrate antigen 19-9; CEA, carcinoembryonic antigen; FIGO, International Federation of Gynecology and Obstetrics; GPS, Glasgow prognostic score.

Organization classification (22). Tumor staging and grading were performed according to the FIGO classification. All patients underwent surgery (total abdominal hysterectomy and bilateral salpingo-oophorectomy), and those with a cancer stage $>1 \mathrm{a}$ and grade 1 underwent pelvic lymph node dissection and adjuvant platinum and taxane chemotherapy. Pelvic lymph node dissection and adjuvant chemotherapy were omitted in EC patients with stage 1a and grade 1 disease.

Measurement of GPS. Pretreatment serum CRP and albumin levels were measured 4 weeks prior to surgery. The pretreatment GPS was classified as follows: Patients with both a high CRP level $(>1.0 \mathrm{mg} / \mathrm{dl})$ and hypoalbuminemia $(<3.5 \mathrm{~g} / \mathrm{dl})$ were assigned a score of 2 , those with only one of these biochemical abnormalities were assigned a score of 1 , and those with neither of these abnormalities were assigned a score of 0 (23).

Statistical analysis. Statistical analyses were conducted with SPSS software for Windows, version 19.0 (SPSS Inc., Chicago, IL, USA). Binomial logistic regression analysis was used for univariate analysis in case of ordered categorical variables. The following clinical factors were used for modeling: Patient age at diagnosis ( $<60$ vs. $\geq 60$ years), stage
Table II. Association of clinicopathological parameters with pretreatment Glasgow prognostic score.

\begin{tabular}{|c|c|c|c|c|c|}
\hline \multirow[b]{2}{*}{ Variables } & \multirow{2}{*}{$\begin{array}{l}\text { No. of } \\
\text { patients }\end{array}$} & \multicolumn{3}{|c|}{ Pretreatment GPS } & \multirow[b]{2}{*}{ P-value } \\
\hline & & 0 & 1 & 2 & \\
\hline $\begin{array}{l}\text { Age at diagnosis, } \\
\text { years }\end{array}$ & & & & & 0.348 \\
\hline$<60$ & 55 & 45 & 6 & 4 & \\
\hline$\geq 60$ & 63 & 46 & 13 & 4 & \\
\hline FIGO stage & & & & & $<0.001$ \\
\hline I, II & 79 & 70 & 8 & 1 & \\
\hline III, IV & 39 & 21 & 11 & 7 & \\
\hline Histology & & & & & 0.007 \\
\hline Endometrioid & 99 & 82 & 12 & 5 & \\
\hline Other & 19 & 9 & 7 & 3 & \\
\hline Grade & & & & & 0.006 \\
\hline G1 & 53 & 47 & 6 & 0 & \\
\hline $\mathrm{G} 2, \mathrm{G} 3$ & 65 & 44 & 13 & 8 & \\
\hline CA19-9, U/ml & & & & & 0.116 \\
\hline$<37$ & 93 & 76 & 13 & 4 & \\
\hline$\geq 37$ & 25 & 16 & 5 & 4 & \\
\hline CEA, ng/ml & & & & & 0.567 \\
\hline$<5.0$ & 97 & 79 & 11 & 7 & \\
\hline$\geq 5.0$ & 21 & 15 & 4 & 1 & \\
\hline
\end{tabular}

CA19-9, carbohydrate antigen 19-9; CEA, carcinoembryonic antigen; FIGO, International Federation of Gynecology and Obstetrics; GPS, Glasgow prognostic score.

(I/II vs. III/IV), histological type (endometrioid vs. others), tumor grade (1 vs. 2/3), pretreatment GPS (0 vs. 1 vs. 2 ), carbohydrate antigen (CA) 19-9 level (<37 vs. $\geq 37 \mathrm{U} / \mathrm{ml}$ ), and carcinoembryonic antigen (CEA) level ( $<5 \mathrm{vs} . \geq 5 \mathrm{ng} / \mathrm{ml}$ ). Progression-free survival (PFS) and overall survival (OS) were the endpoints of the analysis. PFS was defined as the date from initial diagnosis to initial recurrence of disease. Patients with no recurrence at their last follow-up visit were censored at that time. OS was defined as the date from initial diagnosis to death. Patients alive at their last follow-up visit were censored at that time. Kaplan-Meier curves and log-rank tests were used to plot the survival data and determine the statistical significance of survival differences. Variables that were significant $(\mathrm{P}<0.05)$ in the univariate analysis were entered into the multivariate analysis. The Cox's proportional hazards model was used for the prognostic analysis. Data of patients who were lost to follow-up were censored. All reported $\mathrm{P}$-values were two-sided, and $\mathrm{P}<0.05$ was considered to indicate statistically significant differences.

\section{Results}

Patient and clinical characteristics. A total of 118 patients with EC were enrolled. Their clinicopathological characteristics are summarized in Table I. 
Table III. Univariate and multivariate analyses of prognostic factors for progression-free survival.

\begin{tabular}{|c|c|c|c|c|c|c|}
\hline \multirow[b]{2}{*}{ Factors } & \multicolumn{3}{|c|}{ Univariate analysis } & \multicolumn{3}{|c|}{ Multivariate analysis } \\
\hline & Hazard ratio & $95 \% \mathrm{CI}$ & P-value & Hazard ratio & $95 \% \mathrm{CI}$ & P-value \\
\hline Age at diagnosis, years & 2.559 & $1.132-5.784$ & 0.024 & 2.090 & $0.899-4.862$ & 0.087 \\
\hline FIGO stage & 5.2712. & $2.376-11.694$ & $<0.001$ & 3.981 & $1.712-9.256$ & 0.001 \\
\hline Histology & 4.7872. & $.268-10.162$ & $<0.001$ & 2.794 & $1.249-6.248$ & 0.012 \\
\hline Grade & $4.778 \quad 1$. & $.662-13.738$ & 0.004 & $\mathrm{~N} / \mathrm{A}$ & $\mathrm{N} / \mathrm{A}$ & $\mathrm{N} / \mathrm{A}$ \\
\hline Pretreatment GPS & 2.618 & $1.654-4.154$ & $<0.001$ & 1.792 & $1.076-2.985$ & 0.025 \\
\hline CA19-9, U/ml & 0.943 & $0.381-2.332$ & 0.899 & - & - & - \\
\hline $\mathrm{CEA}, \mathrm{ng} / \mathrm{ml}$ & 1.978 & $0.727-5.380$ & 0.181 & - & - & - \\
\hline
\end{tabular}

CA19-9, carbohydrate antigen 19-9; CEA, carcinoembryonic antigen; CI, confidence interval; FIGO, International Federation of Gynecology and Obstetrics; GPS, Glasgow prognostic score; N/A, not available.

Table IV. Univariate and multivariate analyses of prognostic factors for overall survival.

\begin{tabular}{|c|c|c|c|c|c|c|}
\hline \multirow[b]{2}{*}{ Factors } & \multicolumn{3}{|c|}{ Univariate analysis } & \multicolumn{3}{|c|}{ Multivariate analysis } \\
\hline & Hazard ratio & $95 \% \mathrm{CI}$ & $\mathrm{P}$-value & Hazard ratio & $95 \% \mathrm{CI}$ & P-value \\
\hline Age at diagnosis, years & 1.976 & $0.740-5.275$ & 0.174 & - & - & - \\
\hline FIGO stage & 8.6582. & $2.802-26.754$ & $<0.001$ & 5.469 & $1.649-18.137$ & 0.005 \\
\hline Histology & 5.4472. & $2.129-13.940$ & $<0.001$ & 4.214 & $1.346-13.197$ & 0.014 \\
\hline Grade & 3.6981. & $1.070-12.782$ & 0.039 & N/A & N/A & $\mathrm{N} / \mathrm{A}$ \\
\hline Pretreatment GPS & 2.583 & $1.454-4.588$ & $<0.001$ & 2.126 & $1.021-4.428$ & 0.044 \\
\hline CA19-9, U/ml & 1.392 & $0.493-3.927$ & 0.532 & - & - & - \\
\hline $\mathrm{CEA}, \mathrm{ng} / \mathrm{ml}$ & 4.0301. & $1.342-12.101$ & 0.013 & 4.110 & $1.246-13.553$ & 0.020 \\
\hline
\end{tabular}

CA19-9, carbohydrate antigen 19-9; CEA, carcinoembryonic antigen; CI, confidence interval; FIGO, International Federation of Gynecology and Obstetrics; GPS, Glasgow prognostic score; N/A, not available.

A

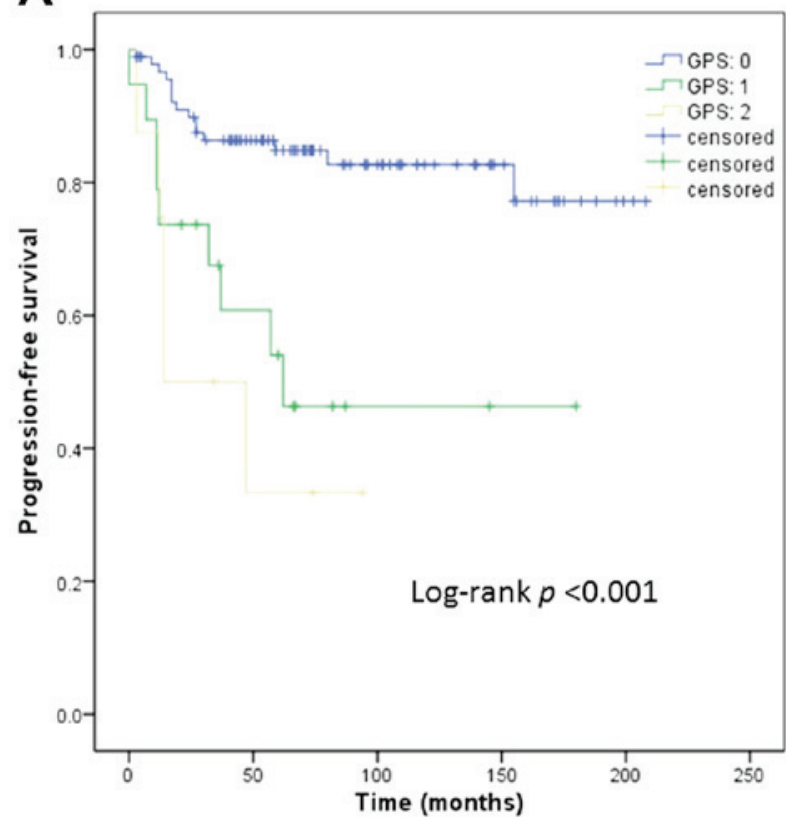

B

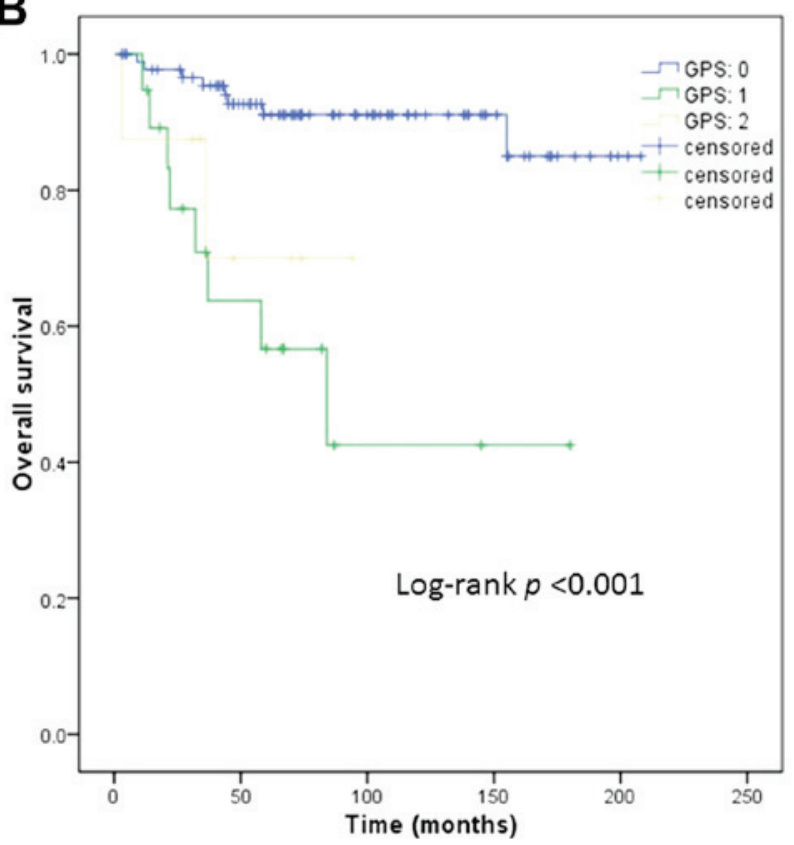

Figure 1. Kaplan-Meier estimates of the prognostic value of a high pretreatment Glasgow prognostic score (GPS) for (A) progression-free survival and (B) overall survival in patients with endometrial carcinoma. 
Associations between clinicopathological parameters and preoperative GPS in patients with EC. Binomial logistic regression analyses (Table II) were used to evaluate the associations between patient clinicopathological factors and pretreatment GPS. Clinical stage $(\mathrm{P}<0.001)$, histological type $(\mathrm{P}=0.007)$ and tumor grade $(\mathrm{P}=0.006)$ were found to be significantly associated with pretreatment GPS.

Univariate and multivariate analyses of prognostic factors in patients with EC. Age, clinical stage, histological type, grade, pretreatment GPS, CA19-9, and CEA levels were investigated in univariate analyses of survival. As regards PFS, age $(\mathrm{P}=0.024)$, stage $(\mathrm{P}<0.001)$, histological type $(\mathrm{P}<0.001)$, grade $(\mathrm{P}=0.004)$ and pretreatment GPS $(\mathrm{P}<0.001 ;$ Fig. $1 \mathrm{~A})$ were found to be significant predictors. Multivariate analysis revealed that advanced stage (III/IV) [hazard ratio $(\mathrm{HR})=3.981 ; 95 \%$ confidence interval (CI): 1.712-9.256; $\mathrm{P}=0.001]$, histological type (except for endometrioid; HR=2.794; 95\% CI: 1.249-6.248; $\mathrm{P}=0.012)$, and high pretreatment GPS $(\mathrm{HR}=1.792 ; 95 \% \mathrm{CI}$ : 1.076-2.985; $\mathrm{P}=0.025)$ were independent negative predictors for PFS (Table III). As regards OS, as shown in Table IV, stage $(\mathrm{P}<0.001)$, histological type $(\mathrm{P}<0.001)$, grade $(\mathrm{P}=0.039)$, pretreatment GPS $(\mathrm{P}<0.001$; Fig. $1 \mathrm{~B})$ and $\mathrm{CEA}$ level $(\mathrm{P}=0.013)$ were found to be significant predictors. The multivariate analysis revealed that advanced stage (stage III/IV) $(\mathrm{HR}=5.469$; 95\% CI: 1.649-18.137; $\mathrm{P}=0.005$ ), histological type (except for endometrioid; HR=4.214; 95\% CI: 1.346-13.197; $\mathrm{P}=0.014$ ), high pretreatment GPS (HR=2.126; 95\% CI: 1.021-4.428; $\mathrm{P}=0.044)$ and CEA level $(\geq 5.0 \mathrm{ng} / \mathrm{ml} ; \mathrm{HR}=4.110 ; 95 \% \mathrm{CI}$ : 1.246-13.553; $\mathrm{P}=0.020)$ were significant independent negative predictors for OS (Table IV).

\section{Discussion}

To the best of our knowledge, this is the first report to demonstrate that a high preoperative GPS is a negative prognostic factor in patients with EC. Using Cox's regression analysis, it was revealed that a high pretreatment GPS is an independent prognosticator in EC, which is consistent with its prognostic ability in other malignancies.

The mechanisms of the correlation between an elevated GPS and poor prognosis remain unclear. As GPS is determined by CRP and albumin levels, proposed explanations include the following: i) Circulating CRP levels may indicate inflammatory status in the tumor microenvironment (23). Tumor growth, invasion and metastasis may be stimulated by inflammation in the tumor microenvironment $(20,24)$. ii) CRP production is stimulated by proinflammatory cytokines, such as interleukin (IL)-6 and tumor necrosis factor (TNF)- $\alpha$, which may promote tumor cell survival, growth and migration (25-27); elevated CRP levels may reflect increased levels of these cytokines. iii) CRP may protect tumor cells from apoptosis. Human CRP binds Fc gamma receptors, and by activating the phosphatidylinositol 3-kinase/Akt, nuclear factor- $\kappa \mathrm{B}$ and extracellular signal-regulated kinase pathways, prevents chemotherapy-induced apoptosis of myeloma cells (28). CRP also increases the secretion of IL-6 and exerts a synergistic effect to protect myeloma cells from chemotherapy-induced apoptosis (25); if these effects occur in EC, CRP may become a treatment target. iv) In addition, serum albumin levels may be decreased by proinflammatory cytokines, such as IL-6 and TNF, via inhibition of albumin production in hepatic cells $(10,26)$; thus, the possible mechanisms underlying the association between serum albumin concentration and survival are similar to those for CRP. Furthermore, since albumin is a marker of nutritional status, pretreatment hypoalbuminemia may indicate pre-existing malnutrition or poor health status (29).

There were certain limitations to the present study, such as its retrospective design. In addition, the GPS was measured only once, as part of a routine examination prior to treatment. The GPS has been shown to be a clinical biomarker that potentially reflects aggressive tumor biology. Therefore, longitudinal studies with continuous GPS determinations over different treatment periods are required to elucidate the association between GPS and prognosis, and the mechanisms underlying this association.

In conclusion, a high pretreatment GPS was found to be correlated with poor surgical outcomes in patients with EC. The pretreatment GPS may represent a cost-effective and convenient predictive marker for the identification of high-risk populations, which may guide clinical decision-making and improve patient outcomes.

\section{Competing interests}

The authors declare that they have no competing interests.

\section{References}

1. Ferlay J, Soerjomataram I, Dikshit R, Eser S, Mathers C, Rebelo M, Parkin DM, Forman D and Bray F: Cancer incidence and mortality worldwide: Sources, methods and major patterns in GLOBOCAN 2012. Int J Cancer 136: E359-E386, 2015.

2. SGO Clinical Practice Endometrial Cancer Working Group, Burke WM, Orr J, Leitao M, Salom E, Gehrig P, Olawaiye AB, Brewer M, Boruta D, Villella J, et al: Endometrial cancer: A review and current management strategies: Part I. Gynecol Oncol 134: 385-392, 2014.

3. Ho CM, Chien TY, Huang SH, Wu CJ, Shih BY and Chang SC: Multivariate analysis of the prognostic factors and outcomes in early cervical cancer patients undergoing radical hysterectomy. Gynecol Oncol 93: 458-464, 2004.

4. Pecorelli S: Revised FIGO staging for carcinoma of the vulva, cervix, and endometrium. Int J Gynaecol Obstet 105: 103-104, 2009.

5. Kamura T, Tsukamoto N, Tsuruchi N, Saito T, Matsuyama T, Akazawa K and Nakano H: Multivariate analysis of the histopathologic prognostic factors of cervical cancer in patients undergoing radical hysterectomy. Cancer 69: 181-186, 1992.

6. Takeda N, Sakuragi N, Takeda M, Okamoto K, Kuwabara M, Negishi H, Oikawa M, Yamamoto R, Yamada H and Fujimoto S: Multivariate analysis of histopathologic prognostic factors for invasive cervical cancer treated with radical hysterectomy and systematic retroperitoneal lymphadenectomy. Acta Obstet Gynecol Scand 81: 1144-1151, 2002.

7. Fotiou S, Vlahos N, Kondi-Pafiti A, Zarganis P, Papakonstantinou K and Creatsas G: Intraoperative gross assessment of myometrial invasion and cervical involvement in endometrial cancer: Role of tumor grade and size. Gynecol Oncol 112: 517-520, 2009

8. Lo KW, Cheung TH, Yim SF and Chung TK: Preoperative hysteroscopic assessment of cervical invasion by endometrial carcinoma: A retrospective study. Gynecol Oncol 82: 279-282, 2001.

9. Haldorsen IS, Berg A, Werner HM, Magnussen IJ, Helland H, Salvesen OO, Trovik J and Salvesen HB: Magnetic resonance imaging performs better than endocervical curettage for preoperative prediction of cervical stromal invasion in endometrial carcinomas. Gynecol Oncol 126: 413-418, 2012. 
10. Guthrie GJ, Charles KA, Roxburgh CS, Horgan PG McMillan DC and Clarke SJ: The systemic inflammation-based neutrophil-lymphocyte ratio: Experience in patients with cancer. Crit Rev Oncol Hematol 88: 218-230, 2013.

11. McMillan DC: Systemic inflammation, nutritional status and survival in patients with cancer. Curr Opin Clin Nutr Metab Care 12: 223-226, 2009.

12. McMillan DC, Elahi MM, Sattar N, Angerson WJ, Johnstone J and McArdle CS: Measurement of the systemic inflammatory response predicts cancer-specific and non-cancer survival in patients with cancer. Nutr Cancer 41: 64-69, 2001.

13. Forrest LM, McMillan DC, McArdle CS, Angerson WJ, Dagg K and Scott HR: A prospective longitudinal study of performance status, an inflammation-based score (GPS) and survival in patients with inoperable non-small-cell lung cancer. Br J Cancer 92: 1834-1836, 2005.

14. Brown DJ, Milroy R, Preston T and McMillan DC: The relationship between an inflammation-based prognostic score (Glasgow Prognostic Score) and changes in serum biochemical variables in patients with advanced lung and gastrointestinal cancer. J Clin Pathol 60: 705-708, 2007.

15. Glen P, Jamieson NB, McMillan DC, Carter R, Imrie CW and McKay CJ: Evaluation of an inflammation-based prognostic score in patients with inoperable pancreatic cancer. Pancreatology 6: 450-453, 2006

16. Ramsey S, Lamb GW, Aitchison M, Graham J and McMillan DC: Evaluation of an inflammation-based prognostic score in patients with metastatic renal cancer. Cancer 109: 205-212, 2007.

17. Omichi C, Nakamura K, Haraga J, Masuyama H and Hiramatsu $Y$ Glasgow prognostic score is an independent marker for poor prognosis with all cases of epithelial ovarian cancer. Cancer Med 5: 1074-1080, 2016.

18. Zhu J, Wang H, Liu CC, Lu Y and Tang H: The Glasgow Prognostic Score (GPS) is a novel prognostic indicator in advanced epithelial ovarian cancer: A multicenter retrospective study. J Cancer Res Clin Oncol 142: 2339-2345, 2016.

19. Nishida T, Nakamura K, Haraga J, Ogawa C, Kusumoto T, Seki N, Masuyama H, Katayama N, Kanazawa S and Hiramatsu Y: The Glasgow prognostic score determined during concurrent chemoradiotherapy is an independent predictor of survival for cervical cancer. Int J Gynecol Cancer 25: 1306-1314, 2015.
20. Polterauer S, Grimm C, Seebacher V, Rahhal J, Tempfer C, Reinthaller A and Hefler L: The inflammation-based Glasgow prognostic score predicts survival in patients with cervical cancer. Int J Gynecol Cancer 20: 1052-1057, 2010.

21. Siegel R, Naishadham D and Jemal A: Cancer statistics, 2013. CA Cancer J Clin 63: 11-30, 2013.

22. Kurman RJ, Carcangiu ML, Herrington CS and Young RH: WHO Classification of Tumors of Female Reproductive Organs. Fourth Edition. Lyon, France: IARC Press 6, 2014.

23. Marnell L, Mold C and Du Clos TW: C-reactive protein: Ligands, receptors and role in inflammation. Clin Immunol 117: 104-111, 2005.

24. Forrest LM, McMillan DC, McArdle CS, Angerson WJ and Dunlop DJ: Evaluation of cumulative prognostic scores based on the systemic inflammatory response in patients with inoperable non-small-cell lung cancer. Br J Cancer 89: 1028-1030, 2003.

25. Candido J and Hagemann T: Cancer-related inflammation. J Clin Immunol 33 (Suppl 1): S79-S84, 2013

26. Elinav E, Nowarski R, Thaiss CA, Hu B, Jin C and Flavell RA Inflammation-induced cancer: Crosstalk between tumours, immune cells and microorganisms. Nat Rev Cancer 13: 759-771, 2013.

27. Grivennikov SI, Greten FR and Karin M: Immunity, inflammation, and cancer. Cell 140: 883-899, 2010.

28. Yang J, Wezeman M, Zhang X, Lin P, Wang M, Qian J, Wan B, Kwak LW, Yu L and Yi Q: Human C-reactive protein binds activating Fcgamma receptors and protects myeloma tumor cells from apoptosis. Cancer Cell 12: 252-265, 2007.

29. Gupta D and Lis CG: Pretreatment serum albumin as a predictor of cancer survival: A systematic review of the epidemiological literature. Nutr J 9: 69, 2010.

This work is licensed under a Creative Commons Attribution-NonCommercial-NoDerivatives 4.0 International (CC BY-NC-ND 4.0) License. 